\title{
Assessment of the Quality of Composite Resin Restorations
}

\author{
Z. A. Ijaimi1,2, N. H. Abu-Bakr1,3*, Y. E. Ibrahim ${ }^{1}$ \\ ${ }^{1}$ Conservative Dentistry Division, Department of Oral Rehabilitation, Faculty of Dentistry, University of \\ Khartoum, Khartoum, Sudan \\ ${ }^{2}$ Department of Restorative Dentistry, College of Dentistry, Najran University, Najran, KSA \\ ${ }^{3}$ Department Clinical Dental Science, College of Dentistry, Princess Nourah Bint Abdelrahman University, \\ Riyadh, KSA \\ Email: ${ }^{*}$ neamat@yahoo.com, ${ }^{*}$ nhabubakr@uofk.edu, ${ }^{*}$ nhabubakr@pnu.edu.sa
}

Received 24 December 2014; accepted 23 January 2015; published 30 January 2015

Copyright (C) 2015 by authors and Scientific Research Publishing Inc.

This work is licensed under the Creative Commons Attribution International License (CC BY).

http://creativecommons.org/licenses/by/4.0/

(c) (i) Open Access

\section{Abstract}

Purpose: To evaluate the quality of the composite restorations. Material and Methods: A total of 246 composite restorations in 125 patients attending the Conservative Dentistry Clinics at the Faculty of Dentistry, University of Khartoum were examined. Both anterior and posterior composite restorations were included. California Dental Association Quality Evaluation System was used for the evaluation. Results: Fifty two percent of all restorations were found to be satisfactory, while the remaining $48 \%$ were not satisfactory. With regard to surface and colour criteria, colour mismatch within the range $(34.8 \%)$ and slight surface roughness $(26.6 \%)$ were the most common defects. The most frequent defects of the anatomical form were restoration overhang $(26.8 \%)$. The majority of the restorations above 4 years old were of unacceptable anatomical form $(66.7 \%)$, and their marginal integrity was less acceptable than more recent restorations $(46.7 \%)$. Conclusions: Forty eight percent of the examined composite restorations needed to be replaced, and the unacceptable anatomic form was the main cause of failure of composite restorations.

\section{Keywords}

Composite Resin Restorations, Marginal Defect, Overhang Restoration, Colour Mismatch

\section{Introduction}

Direct restorations provide a reliable treatment to replace the lost dental structure, with a low cost, less sound

"Corresponding author. 
dental structure removal and also good clinical performance when compared to indirect restorations [1]-[3]. Amalgam is used to be considered the best restorative material for posterior teeth. However, its use has significantly declined due to esthetic reasons and potential toxicity of mercury from amalgam restorations [4]. In 1990's, composite resin was the material of choice for anterior restorations due to the fulfillment of the esthetic expectations of patients. It was also indicated for posterior restorations, yet in small occlusal or occluso-proximal cavities, preferably with little occlusal function and in premolars [5]. In recent years, however, patient demands for non-metallic restorations increased the use of composite materials for aesthetic reasons; even in posterior teeth, it became the most common used \& preferable direct restoration [1]. The currently available universal composites, microhybrid, nanohybrid or nano-particulate, present volumetric shrinkage lower than $4 \%$, mechanical strength, polishability, polish retaining and wear resistance. Such improvements associated to the state-of-the-art placement technique have led to a clinical behavior comparable to that of amalgam restorations [6]. In addition, the philosophical shift towards the preservation of tooth structure resulting from the minimal intervention dentistry concept increased the indication of composites as adhesive materials [2]. Expectations are that the clinical behavior of these restorations might have been favored by the clinical experience acquired during that decade. Many restorations judged to be clinically unsatisfactory often continued to function adequately for several more years before being replaced. In contrast to this observation, other restorations judged to be satisfactory were sometimes replaced soon after such clinical assessments were made [7]. Although there are many studies addressing failure/longevity of the dental restorations, many of these do not provide useful information, as the definition of failure is often not given. There is variation between studies with regard to definition of failure with a variation from minor deterioration to a need for operative intervention or replacement of a restoration all being cited [8] [9]. Failure of a restoration may take many forms and may be due to major defects (such as fracture and loss of a portion of the supporting tooth or restoration) or may be due to minor defects such as marginal deficiencies, staining or microleakage, and when a restoration has failed, but does not involve loss of restoration or tooth bulk, it is unlikely that the failure would be noticed by the patient unless there are symptoms or there is a visible aesthetic problem [9]. The aim of the present study was to evaluate the quality of composite resin restorations.

\section{Materials and Methods}

The study was approved by the institutional Ethics Committee (Faculty of dentistry, University of Khartoum) and the patients signed a writing consent to be included in the study. All patients with composite resin restoration attending the conservative dentistry clinic, faculty of dentistry, University of Khartoum were examined over a six month period. A total of 246 composite restorations in 125 patients were the sample size of the present study.Inclusive criteria were all direct anterior and posterior composite restorations. Exclusive criteria were indirect composite restorations were excluded from this study, together with teeth restoration with any other restorative material such as glass ionomer restoration. A structured data collection form, for quantitative and qualitative data collection has been developed. All clinical examination was conducted under chair light except for restoration shade assessment which was done under day light. Restored teeth have been isolated first using cotton rolls and then dried with air-syringe. The tooth number, cavity class (G.V. Black Classification), and restoration age were recorded. The composite restorations quality was evaluated according to California Dental Association Quality Evaluation System [10]. This evaluation considers three major criteria which are the surface and color, anatomical form and the marginal integrity of the restoration. Restorations rated into four rates (R, S, $\mathrm{T}$ and $\mathrm{V}$ from excellent to totally unacceptable, respectively) with the first two rates fall in the range of acceptability, and the last two rates fall in the range of unacceptability (Table 1). Accordingly a judgment has been made about the restoration, whether to be retained or replaced either immediately or in the future. The data was analyzed using SPSS. Chi-squire test was used to compare the relation between the categorical variables at a confidence level of 95\% and significant level of 5\%. P value less than 0.05 was considered as significant.

\section{Results}

A total number of 246 direct composite restorations in 125 adult patients were examined. When all three characteristics i.e. surface and colour, anatomical form and marginal integrity were considered, 52\% of all restorations were acceptable. Of the total restorations, 58.5\% were anterior and $41.5 \%$ were posterior restorations. Within the anterior teeth group, the central incisor was the most frequently restored tooth, while in posterior 
teeth the premolars were encountered more than the molars. The maxillary teeth were restored more than mandibular teeth (Table 2). The distribution of the restorations according to cavity type (G.V. Black classification) showed that class IV was the most frequent (31.3\%), followed by class III (21.5\%), class II (20.7\%), class I (16.3\%) while class $\mathrm{V}$ was the least $(10.2 \%)$. More than one third (35.8\%) of the examined restorations were placed in a period less than one year from the data collection time, and restorations served more than 5 years represented only $8.6 \%$. With regard to surface and colour criteria, colour mismatch within the range (34.8\%) and slight surface roughness (26.6\%) were the most common defects. Anatomically acceptable restorations were $55.7 \%$ compared to $44.3 \%$ unacceptable ones of the total examined restorations. The most commonly reported defect was overhang, which was found in about one of every four restorations. Restoration's slight over-contour detected in $13.4 \%$, and almost a same number (13.8\%) of restorations showed an unacceptable type of overcontour, which cannot be adjusted properly (Figure 1). Class I was the most anatomically acceptable (87.5\%). Chi squire Test was performed and the relation was statistically significant $(P$ value $=0.001)$ while, class V was the least acceptable one (36\%). Eighty eight percent of the restorations were of acceptable quality of marginal condition. Of these, about three of each four restorations are of an excellent marginal quality, and only $12 \%$ of all restorations have unacceptable marginal integrity (Table 3). The middle group restorations (2 - 3 and 3 - 4 years) scored more than others in the unacceptable range. Chi squire Test was performed and the result was statistically significant $(\mathrm{P}$ value $=0.015$ ). When comparing the Anatomical form with the age of the restoration, the older-aged restorations ( 4 - 5 and above 5 years restorations) recorded the higher percentage in the unacceptable area, and the result was statistically significant $(\mathrm{P}$ value $=0.019)($ Table 4$)$. Results also showed that $15 \%$ of the restorations were discoloured.

Table 1. Quality evaluation criteria according to the California Dental Association (CDA) [10].

\begin{tabular}{ccc}
\hline Rating scale & Criteria \\
\hline Satisfactory & $\mathrm{R}$ "Romeo" & $\begin{array}{c}\text { Excellent clinical quality or performance } \\
\text { Acceptable clinical quality or performance }\end{array}$ \\
Non-satisfactory & $\mathrm{T}$ "Tierra" & $\begin{array}{c}\text { Clinical quality or performance, which must be repeated, } \\
\text { replaced, repaired, or corrected to avoid future } \\
\text { damage for the patient }\end{array}$ \\
V "Victor" & $\begin{array}{c}\text { Clinical quality or performance, which had to be repeated, } \\
\text { replaced, repaired, or corrected immediately due to a } \\
\text { damage occurring for the patient at that time }\end{array}$ \\
\hline
\end{tabular}

Table 2. Distribution of the examined restorations.

\begin{tabular}{|c|c|c|c|}
\hline Tooth & Jaw & Frequency & Percent \\
\hline \multirow{2}{*}{ Central incisor } & Upper & 77 & $31.3 \%$ \\
\hline & Lower & 0 & $0.0 \%$ \\
\hline \multirow{2}{*}{ Lateral incisor } & Upper & 37 & $15.0 \%$ \\
\hline & Lower & 2 & $0.8 \%$ \\
\hline \multirow{2}{*}{ Canine } & Upper & 22 & $9.0 \%$ \\
\hline & Lower & 6 & $2.4 \%$ \\
\hline \multirow{2}{*}{ Premolar } & Upper & 36 & $14.6 \%$ \\
\hline & Lower & 18 & $7.3 \%$ \\
\hline \multirow{2}{*}{ Molar } & Upper & 26 & $10.6 \%$ \\
\hline & Lower & 22 & $9.0 \%$ \\
\hline \multicolumn{2}{|c|}{ Total } & 246 & $100 \%$ \\
\hline
\end{tabular}




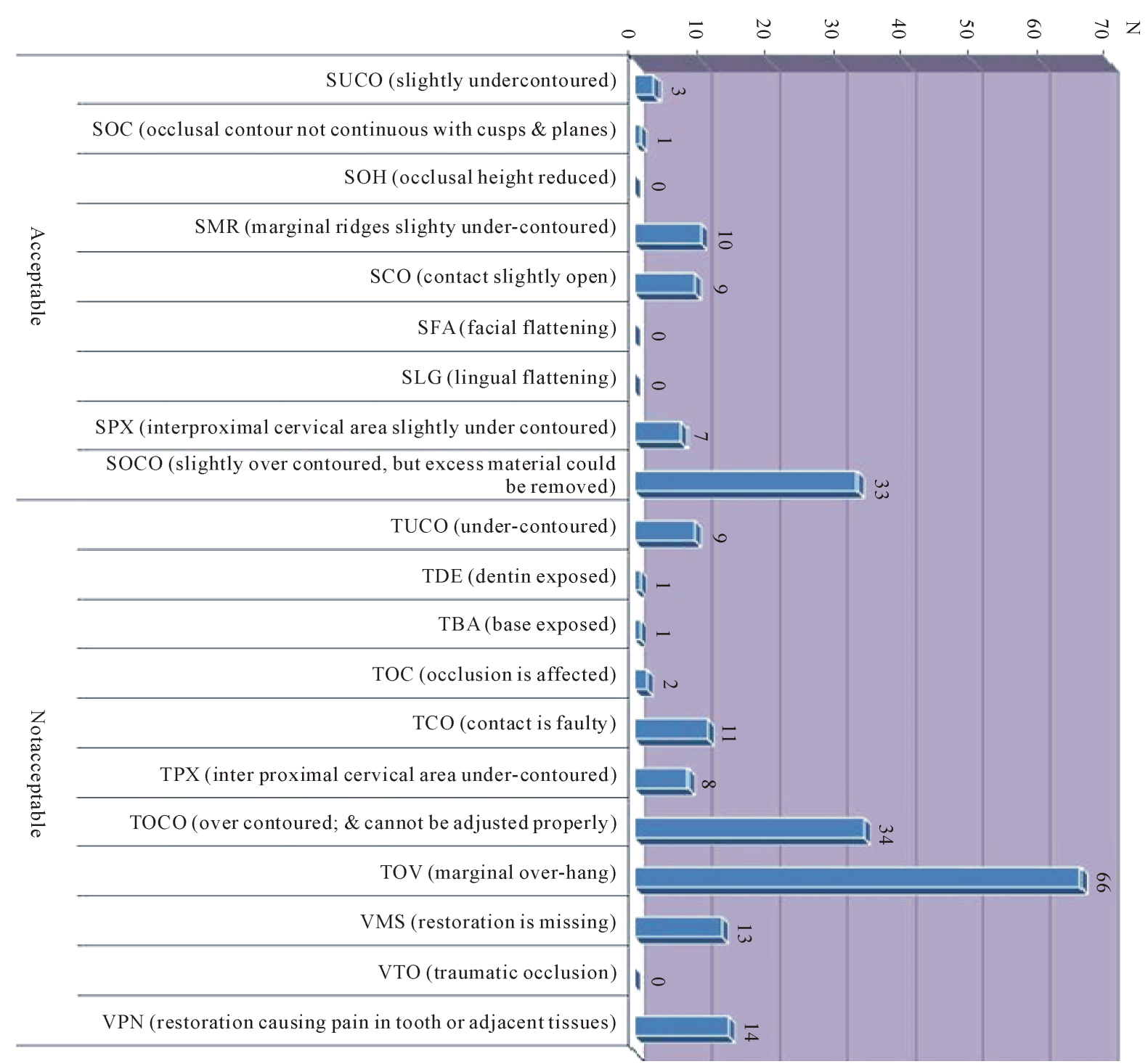

Figure 1. Anatomical form defects of the examined composite resin restoration.

Table 3. Association between cavity class and marginal integrity quality.

\begin{tabular}{cccc}
\hline Cavity & Acceptable & Not acceptable & Total \\
\hline Class I & 37 & 2 & 39 \\
& $94.9 \%$ "R"** & $5.1 \%$ "T"* & $100 \%$ \\
Class II & 40 & 10 & 50 \\
& $80 \%$ "R, S"* & $20 \%$ "V”* & $100 \%$ \\
Class III & 44 & 7 & 51 \\
& $86.3 \%$ "R, S"* & $13.7 \%$ "V"** & $100 \%$ \\
Class IV & 64 & 8 & 72 \\
& $88.9 \%$ "R, S"* & $11.1 \%$ "V"** & $100 \%$ \\
Class V & 20 & 1 & 21 \\
& $95.2 \%$ "R, S"* & $4.8 \%$ "V"** & $100 \%$ \\
Total & 205 & 28 & 246 \\
& $88 \%$ & $12 \%$ & $100 \%$ \\
\hline
\end{tabular}

*Quality evaluation criteria according to CDA. 
Table 4. Association between the anatomical form quality and the age of the restoration.

\begin{tabular}{cccc}
\hline Age & Acceptable & Not acceptable & Total \\
\hline 0 - 1 year & 58 & 30 & 88 \\
& $(65.9 \%)$ & $(34.1 \%)$ & $100 \%$ \\
1 - 2 years & 22 & 27 & 49 \\
& $(44.9 \%)$ & $(55.1 \%)$ & $100 \%$ \\
2 - 3 years & 37 & 29 & 66 \\
& $(56.1 \%)$ & $(43.9 \%)$ & $100 \%$ \\
3 - 4 years & 11 & 5 & 16 \\
& $(68.75 \%)$ & $(31.25 \%)$ & $100 \%$ \\
4 - 5 years & 1 & 5 & 6 \\
& $(16.7 \%)$ & $(83.3 \%)$ & $100 \%$ \\
Above 5 years & 8 & 13 & 21 \\
& $(38.1 \%)$ & $(61.9 \%)$ & $100 \%$ \\
Total & 137 & 109 & 246 \\
& $(55.7 \%)$ & $(44.3 \%)$ & $100 \%$ \\
\hline
\end{tabular}

$P$ value $=0.001$

\section{Discussion}

There is clearly an increasing demand for aesthetic dental restorations; the creation of perfect direct restorations has long been an elusive goal because of the imperfect optical properties of composite resins and also because of improper clinical procedures. The results of the present investigation showed that Fifty two percent of the total restorations were acceptable, while the remaining $48 \%$ were of unacceptable quality and had to be replaced. Maintaining a shade match to the tooth over time is important for clinical success. Colour mismatch within the range of tooth shade was the most frequently found defect (34.8\%). Special attention should be given to matching the colour of the natural tooth with the composite material. The shade of the tooth should be determined before the teeth are subjected to any prolonged drying, because dehydrated teeth become lighter in shade as a result of a decrease in translucency [11]. Optical properties of resin composites change with time, especially related to surface degradation and chemical reaction of the tertiary amine accelerator [12]. The surface and colour results in this study differ from the results found by Vilma et al. in Lithuania (2004) [13].

Evaluation of the anatomical form of the restorations in the present study, revealed that $44.3 \%$ of the restorations were anatomically unacceptable, which approximates the result reported by Vilma et al. in Lithuania (47.58\%) [13]. From literature it is known that overhanging restorations promote gingivitis or lead to periodontal diseases due to local accumulation of bacterial plaque rather than resulting in mechanical irritation. Epidemiological and clinical experimental studies have demonstrated close associations between such iatrogenic factors and the pathogenesis of local periodontal lesions [14]-[17]. In the present investigation overhang restoration had been detected in (26.8\%) of the restorations. A statistically significant relation between the restoration age and the anatomical form was found. The 4 - 5 years restorations and restorations above 5 years age, showed higher percentages of unacceptability ( $83.3 \%$ and $61.9 \%$ respectively). This may be due to the inherent problem of reduced wear resistance of the composite materials. The relation between the restoration age and the marginal integrity showed that, the older restorations ( 4 - 5 years and above 5 years) showed a lower acceptability in the marginal integrity (40\% and $66.7 \%$, respectively). This result is statistically significant, and this is possibly due to the marginal ditching with the advance in age of the restoration and the ensuing microleakage. Marginal gap formation is known as a common disadvantage of composite resins due to polymerization shrinkage. It is uncertain whether the practitioners use the incremental or bulk application of the material. Discolouration is still a significant clinical problem with the resin composite materials, and esthetic failure is one of the most common reasons for the replacement of restorations [18]. In the present study, the discoloured restorations represented (15\%) of the total restorations. Results also indicated that class II recorded the highest unacceptable marginal integrity percentage compared to other classes $(20 \%)$. The inaccessibility of the cervical area of class II preparations and the problem of moisture control in the posterior region further hinder good marginal adaptation [19]. There may be a moisture control problem, or lack of experience and familiarity with class II composite applica- 
tion. Ahmed et al. (2000) reported that, only 2\% of practitioners in Sudan use the rubber dam for root canal treatment [20]. Beside restoration techniques, the caries risk factor plays a significant role in restoration survival. In a recent investigation conducted by Opdam et al. results showed that in the high-risk patients group, both composite and amalgam restorations showed comparable performance, with amalgam performing better on smaller restorations. From the same study it was concluded that caries risk of patients plays a significant role in restoration survival [21]. A recent investigation showed that after five years performance the indirect composite resin inlays and direct composite resin restorations exhibited a lesser annual failure rate of $2.5 \%$ and $1.6 \%$, respectively [22]. The limitation of the present study were the sample size was small relatively also further studies investigating the types of restorative materials used in relation to the caries risk factor are recommended.

\section{Conclusion}

Within the limitations of the study, it is concluded from the evaluation of the composite restorations that $48 \%$ of the composite restorations are of unacceptable quality and must be replaced. Not acceptable anatomic form is the main reason indicating the need for replacement (44.3\%). Colour mismatch, surface roughness and overhang are the most common defects of the composite restorations encountered in this study.

\section{References}

[1] Brunthaler, A., König, F., Lucas, T., Sperr, W. and Schedle, A. (2003) Longevity of Direct Resin Composite Restorations in Posterior Teeth. Clinical Oral Investigations, 7, 63-70. http://dx.doi.org/10.1007/s00784-003-0206-7

[2] Manhart, J., Chen, H., Hamm, G. and Hickel, R. (2004) Buonocore Memorial Lecture. Review of the Clinical Survival of Direct and Indirect Restorations in Posterior Teeth of the Permanent Dentition. Operative Dentistry, 29, 481-508.

[3] Da Rosa Rodolpho, P.A., Cenci, M.S., Donassollo, T.A., Loguércio, A.D. and Demarco, F.F. (2007) A Clinical Evaluation of Posterior Composite Restorations: 17-Year Findings. Journal of Dentistry, 34, 427-435. http://dx.doi.org/10.1016/j.jdent.2005.09.006

[4] Opdam, N.J.M., Bronkhorst, E.M., Roeters, J.M. and Loomans, B.A.C. (2007) A Retrospective Clinical Study on Longevity of Posterior Composite and Amalgam Restorations. Dental Materials, 23, 2-8. http://dx.doi.org/10.1016/j.dental.2005.11.036

[5] Lynch, C.D., McConnell, R.J. and Wilson, N.H.F. (2007) Trends in the Placement of Posterior Composites in Dental Schools. Journal of Dental Education, 71, 430-434.

[6] Opdam, N.J.M., Loomans, B.A.C., Roeters, F.J.M. and Bronkhorst, E.M. (2004) Five Year Clinical Performance of Posterior Resin Composite Restorations Placed by Dental Students. Journal of Dentistry, 32, 379-383. http://dx.doi.org/10.1016/j.jdent.2004.02.005

[7] Smalles, R.J. and Webster, D.A. (1993) Restoration Deterioration Related to Later Failure. Operative Dentistry, 18, 130-137.

[8] Qualtrough, A.J.E., Satterthwaite, J.D., Morrow, L.A. and Brunton, P.A. (2005) Principles of Operative Dentistry. Blackwell, 154-155.

[9] Djemal, S., Setchell, D., King, P. and Wickens, J. (1999) Long Term Survival Characteristics of 832 Resin-Retained Bridges and Splints Provided in a Post-Graduate Teaching Hospital between 1978 and 1993. Journal of Oral Rehabilitation, 26, 302-320. http://dx.doi.org/10.1046/j.1365-2842.1999.00374.x

[10] Cvar, J. and Ryge, G. (2005) Reprint of Criteria for the Clinical Evaluation of Dental Restorative Materials. Clinical Oral Investigations, 9, 215-232. http://dx.doi.org/10.1007/s00784-005-0018-z

[11] Roberson, T.M., Heymann, H.O. and Swift, E.J. (2002) Sturdevant's Art \& Science of Operative Dentistry. 4th Edition, Mosby Inc., Orlando, 476-483.

[12] Powers, J.M. and Fan, P.L. (1980) Erosion of Composite Resins. Journal of Dental Research, 59, 815-819. http://dx.doi.org/10.1177/00220345800590051101

[13] Brukiene, V., Aleksejuniene, J. and Balciuniene, I. (2005) Dental Restorations Quality in Lithuanian Adolescents. Stomatologija, Baltic Dental and Maxillofacial Journal, 7, 103-109.

[14] Gilmore, N. and Sheiham, A. (1971) Overhanging Dental Restorations and Periodontal Disease. Journal of Periodontology, 42, 8-12. http://dx.doi.org/10.1902/jop.1971.42.1.8

[15] Tervonen, T. and Ainamo, J. (1986) Relative Influence of Calculus and Overhangs of Fillings on the Frequency of Score 2 of the CPITN. Community Dentistry and Oral Epidemiology, 14, 136-217. http://dx.doi.org/10.1111/j.1600-0528.1986.tb01516.x 
[16] Jansson, L., Ehnevid, H., Lindskog, S. and Blomlof, L. (1994) Proximal Restorations and Periodontal Status. Journal of Clinical Periodontology, 21, 577-582. http://dx.doi.org/10.1111/j.1600-051X.1994.tb00746.x

[17] Hakkarainen, K. and Ainamo, J. (1980) Influence of Overhanging Posterior Tooth Restorations on Alveolar Bone Height in Adults. Journal of Clinical Periodontology, 7, 114-120. http://dx.doi.org/10.1111/j.1600-051X.1980.tb01954.X

[18] Pires-de-Souza Fde, C., Garcia Lda, F., Hamida, H.M. and Casemiro, L.A. (2007) Color Stability of Composites Subjected to Accelerated Aging after Curing Using Either a Halogen or a Light Emitting Diode Source. Brazilian Dental Journal, 18, 119-123.

[19] Mjör, I.A. (1998) The Location of Clinically Diagnosed Secondary Caries. Quintessence International, 29, $313-317$.

[20] Ahmed, M.F., Elseed, A.I. and Ibrahim, Y.E. (2000) Root Canal Treatment in General Practice in Sudan. International Endodontic Journal, 33, 316-319. http://dx.doi.org/10.1046/j.1365-2591.2000.00282.X

[21] Opdam, N., Bronkhorst, E., Loomans, B. and Huysman, M. (2010) 12-Year Survival of Composite vs. Amalgam Restorations. Journal of Dental Research, 89, 1063-1067. http://dx.doi.org/10.1177/0022034510376071

[22] Cetin, A.R., Unlu, N. and Cobanoglu, N. (2013) A Five-Year Clinical Evaluation of Direct Nanofilled and Indirect Composite Resin Restorations in Posterior Teeth. Operative Dentistry, 38, 1-11. 
Scientific Research Publishing (SCIRP) is one of the largest Open Access journal publishers. It is currently publishing more than 200 open access, online, peer-reviewed journals covering a wide range of academic disciplines. SCIRP serves the worldwide academic communities and contributes to the progress and application of science with its publication.

Other selected journals from SCIRP are listed as below. Submit your manuscript to us via either submit@scirp.org or Online Submission Portal.
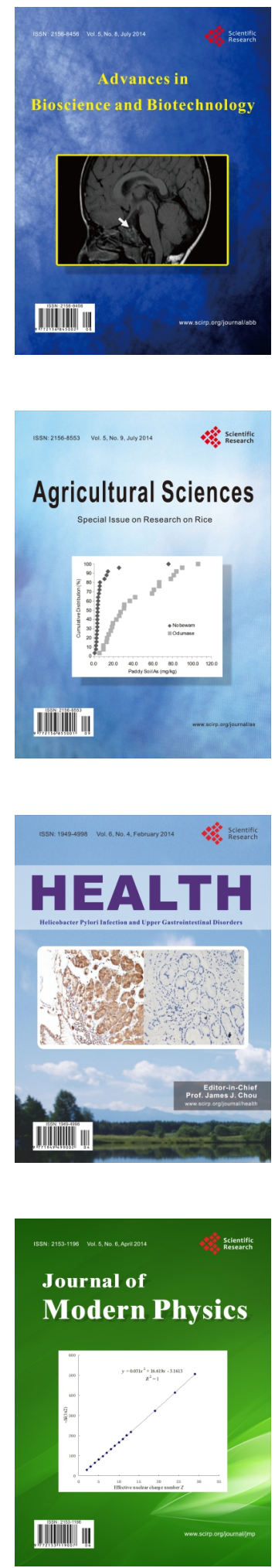
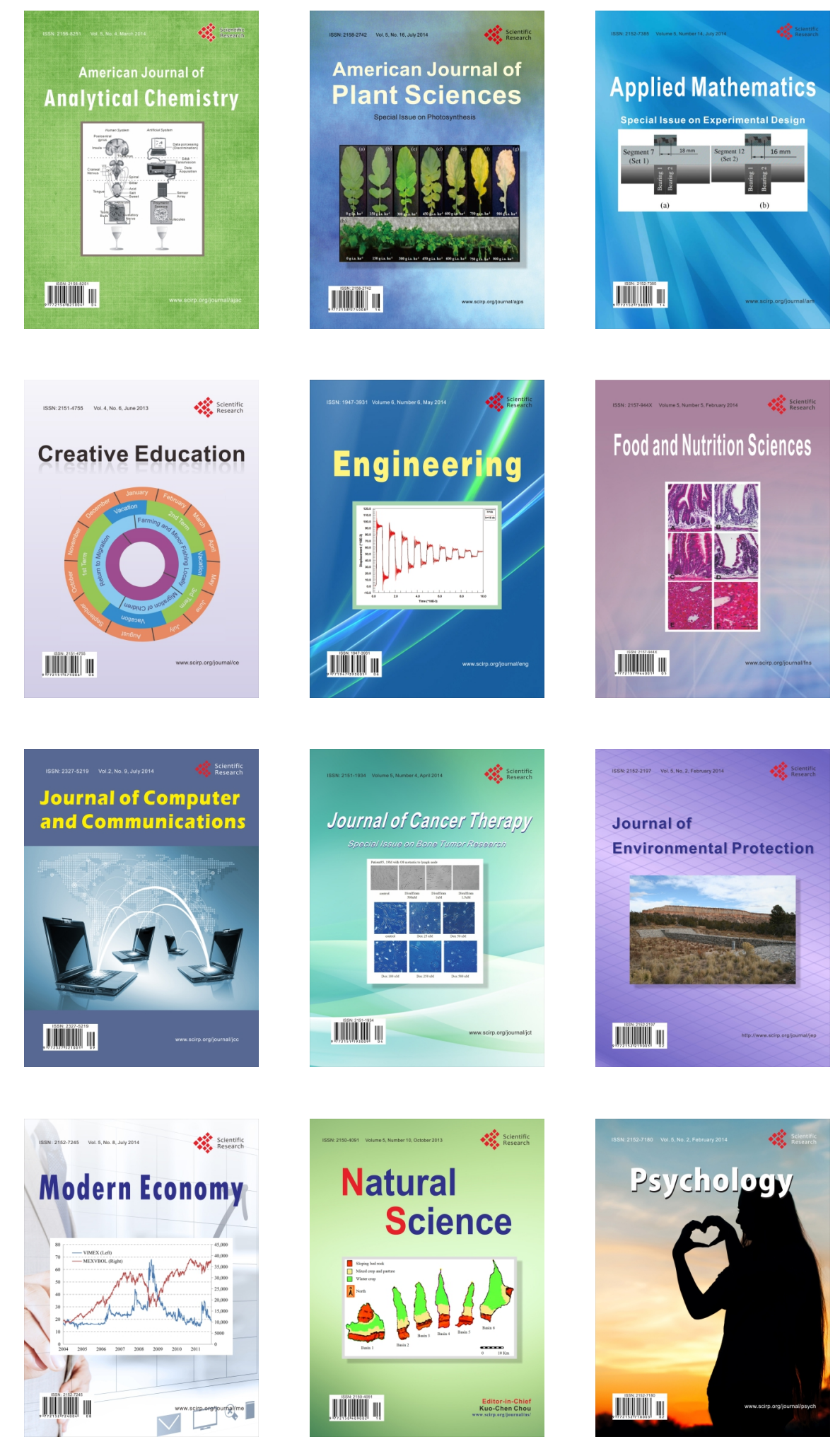